\title{
Gynaecological Malignancies Among a Representative Population of Batticaloa, Sri Lanka
}

\author{
Markandu Thirukumar $^{1}$, Ahilan Sinnathurai ${ }^{2}$ \\ 1. Clinical Science, Faculty of Health Care Sciences, Eastern University, Batticaloa, LKA 2. Pathology, Teaching \\ Hospital, Batticaloa, LKA
}

Corresponding author: Markandu Thirukumar, dr.thiru10@yahoo.com

\section{Abstract \\ Background}

Genital tract malignancies have a significant contribution to morbidity and mortality, particularly in resource-poor countries, including Sri Lanka. The distribution of such tumours varies from region to region.

\section{Methodology}

This was a retrospective, observational study at the Teaching Hospital, Batticaloa for five and a half years, from January 2012 to June 2017, and aimed at analyzing the pattern of gynaecological malignancies. All the histologically confirmed gynaecological cancers arising from the uterine cervix, endometrium, ovary, vagina, and vulva were included in the analysis.

\section{Results}

There were 508 cervical specimens to study histopathology of the cervix, 1,884 gynaecological specimens to study the endometrial histopathology, 537 ovarian specimens, and 92 vaginal and vulval specimen were sent for their histopathological study during the same period. About 143 genital tract malignancies had been diagnosed. There were 52 cervical malignancies (36.36\%) and 52 ovarian malignancies (36.36\%). The second commonest (20.28\%) was endometrial malignancy. Vaginal malignancy was at fourth place (4.9\%). Vulval malignancy was $2.1 \%$. The peak age distribution of malignancies (55.24\%) was mainly in the $40-59$ years age range. The incidence of cervical and ovarian malignancies peaked at 40-59 years, with 32/52 (61.54\%) and 26/52 (50\%) of the diagnosed cases, respectively.

\section{Conclusion}

Cervical cancer and ovarian cancer accounted for almost $72.73 \%$ of the entire gynaecological malignancies in this study, and both of them have the same peak incidence in the 40-59 age group. This study also showed that $43.36 \%$ of total female genital tract tumours are Human Papilloma Virus-associated cancers. They are

Review began 01/15/2021 Review ended 01/27/2021 Published 01/27/2021

๑) Copyright 2021

Thirukumar et al. This is an open access article distributed under the terms of the Creative Commons Attribution License CC-BY 4.0., which permits unrestricted use, distribution, and reproduction in any medium, provided the original author and source are credited. not only preventable by certain strategies but also identifiable and manageable at the precancerous stage.

Categories: Obstetrics/Gynecology, Oncology

Keywords: gynaecological malignancies, cervical cancer, corpus uteri cancer, histopathological subtypes, batticaloa, sri lanka

\section{Introduction}

Genital tract malignancies have a significant contribution to morbidity and mortality, particularly in resource-poor countries, including Sri Lanka, where poor awareness and late presentation also prevail. Globally, gynaecological malignancies account for $10 \%$ of new malignancy cases in women and $12 \%$ of cancer deaths [1]. Most of the gynaecological malignancies differ in their frequency and patterns from one region to another. These wide variations in incidence could be because of the health-seeking behaviour of the women and services for organized screening for cervical malignancies, which is the commonest gynaecological malignancy in women worldwide [2,3,4]. In Sri Lanka, Human papillomavirus vaccination was introduced into the national vaccination programme in 2017 . Two doses of vaccination are given at a six-month interval to students on completion of 10 years of age. The benefit of this primary preventive strategy is yet to be seen.

Squamous cell cervical carcinoma is the commonest female genital tract cancer in sub-Saharan Africa. Endometrial carcinoma is the commonest female genital tract cancers in North America and Northern Europe. The incidence of ovarian cancer has considerable geographical variation. Vulval and vaginal malignancies are rare and their highest incidence in the sixth decade of life [5].

In Sri Lanka, the incidence (crude rate) of cervix uteri and ovarian malignancies in 2014 were 9.8 and 8.4 per 100,000 , respectively. They are the third and fourth commonest cancers in Sri Lanka. Breast and thyroid carcinoma were the first and second commonest during the same period. The incidence of uterine carcinoma 
was 5.4/100,000 population and was at the seventh place [6].

Sri Lanka is an island in the Indian Ocean with 21 million habitants that live in a land area of approximately $62,700 \mathrm{~km} 2$. The adult literacy rate is $89.7 \%$ for females and $92.6 \%$ for males. We conducted this study at the Teaching Hospital, Batticaloa, which is in the Eastern Province of Sri Lanka.

This was a hospital-based study. As this is the only tertiary hospital with better health care facilities in this region, approximately $100 \%$ of the malignancies are treated here. Further, the study population included most of the diagnosed women with cancer from this region and therefore it could reflect the characteristics of the Batticaloa population; only a minority of women living in the region sought care outside this region. Therefore, this study reflects the gynaecological malignancies in this region despite it being a hospital-based study.

\section{Materials And Methods}

This was a retrospective, observational study at the Teaching Hospital, Batticaloa. This study included all patients that were diagnosed with gynaecological cancer over five and a half years, from January 2012 to June 2017, and aimed to analyze the pattern of gynaecological malignancies. All the histologically confirmed gynaecological cancers arising from the uterine cervix, endometrium, ovary, vagina, and vulva were included in the analysis. We collected the case records of all relevant patients with confirmed gynaecological cancer from medical records. They included the following details: age of patients, site of the tumour, and histopathological diagnosis.

The ethical review committee of the Faculty of Health Care Sciences, Eastern University, Sri Lanka issued this research approval - (EUSL/FHCS/ERC/2017/21). We processed data using SPSS version 21 (IBM Corp., Armonk, NY, USA). Descriptive statistics methods were used to analyze the results as whole numbers, percentages, tables, and charts.

\section{Results}

There were 508 cervical specimens taken to study the histopathology of the cervix. It composed of a cervical biopsy from a punch biopsy or cone biopsy and cervical polypectomy. The specimens of endometrium were taken by endosampling, dilatation, and curettage for the evaluation of several symptoms and signs, such as abnormal uterine bleeding, lower abdominal pain, per vaginal bloody or brownish discharge. There were 1,884 gynaecological specimens to study endometrial histopathology. Among them, 1,642 specimens were adequate for a comprehensive diagnosis, and the remaining 242 (12.8\%) were inadequate for reporting. About 242 (12.8\%) of endometrial specimens were inadequate for a comprehensive diagnosis. We studied the histopathological pattern of 537 ovarian specimens. They were ovarian cysts from cystectomy, oophorectomy, salpingo-oophorectomy, and part of total abdominal hysterectomy (TAH). Ninety-two vaginal and vulval specimen were sent for their histopathological study during the same period.

There were 143 genital tract malignancies diagnosed from a total of 3,021 specimens for histopathology report, and we used all the cases for analysis. There were 52 cervical malignancies and 52 ovarian malignancies. Endometrial malignancy was the second commonest. Vaginal malignancy was at fourth place (Table 1).

\begin{tabular}{|c|c|c|}
\hline Site of tumour & Frequency (N=143) & Percentage (\%) (100) \\
\hline Cervix & 52 & 36.36 \\
\hline Ovary & 52 & 36.36 \\
\hline Endometrium & 29 & 20.28 \\
\hline Vagina & 7 & 4.90 \\
\hline Vulva & 3 & 2.10 \\
\hline
\end{tabular}

TABLE 1: Frequency distribution of the gynaecological malignancies by sites

The peak age of occurrence of gynaecological malignancies was in the age range of 40-59 years with 79 patients (55.24\%), followed by 60-69 years with 41 cases (28.67\%), and 20 -39 years with 16 cases (11.19\%). The incidence of malignancies was $0.70 \%$ in the $<19$ years age group and $4.20 \%$ in the $70-79$ years age group.

The distribution of the various gynaecological malignancies by age is also shown in Table 2. Majority of the cases of cervical malignancy were diagnosed between $40-59$ years, with 32 out of 52 cases (61.54\%) occurring in the fourth decade of life. Ovarian malignancy had a peak incidence in the age range of $40-59$ years. 20 out of the 29 cases (68.97\%) of endometrial cancer were diagnosed in the 40-59 


\section{Cureus}

years age range. The peak age of incidence of vaginal cancer was in the age range of 60-69 years, where five out of seven cases $(71.42 \%$ ) were found. Only three cases of vulval cancer were documented in the study period and they all were from the 60-69-year age group.

\begin{tabular}{|c|c|c|c|c|c|c|c|}
\hline Age & Cervical (52) & Ovarian (52) & Endometrial (29) & Vaginal (7) & Vulva (3) & Total (143) & Percentage (\%) \\
\hline$<19$ & - & 1 & - & - & - & 1 & 0.70 \\
\hline $20-39$ & 4 & 10 & 2 & - & - & 16 & 11.19 \\
\hline $40-59$ & 32 & 26 & 20 & 1 & - & 79 & 55.24 \\
\hline $60-69$ & 11 & 15 & 7 & 5 & 3 & 41 & 28.67 \\
\hline 70-79 & 5 & - & - & 1 & - & 6 & 4.20 \\
\hline
\end{tabular}

\section{TABLE 2: Age distribution of gynaecological malignancies}

Table 3 shows that the main histological type of cervical cancer was squamous cell carcinoma, observed in 45 (84.6\%) patients, while six (11.5\%) patients showed adenocarcinoma. Adenocarcinoma was the only histological type of endometrial cancer seen, with 29 patients (100\%). Similarly, all three vulval malignancies were squamous cell carcinoma type (100\%). Most vaginal carcinoma $(71.42 \%)$ were squamous cell carcinoma. Interestingly, one very rare type of vaginal cancer, malignant melanoma, was also reported during this study period. Among ovarian cancers, epithelial tumours were observed in 41 (78.85\%) patients, followed by germ cell tumours in six (11.54\%) patients, and sex cord tumour in five (9.61\%) patients. 


\section{Cureus}

\begin{tabular}{|c|c|c|}
\hline Histological Type & Frequency & Percentage \\
\hline \multicolumn{3}{|l|}{ Cervix } \\
\hline Squamous cell carcinoma & 45 & $84.6 \%$ \\
\hline Adenocarcinoma & 6 & $11.5 \%$ \\
\hline Infrequent tumour subtypes & 1 & $1.9 \%$ \\
\hline Total & 52 & $100 \%$ \\
\hline \multicolumn{3}{|l|}{ Corpus Uteri } \\
\hline Adenocarcinoma & 29 & $100 \%$ \\
\hline \multicolumn{3}{|l|}{ Vulva } \\
\hline Squamous cell carcinoma & 3 & $100 \%$ \\
\hline \multicolumn{3}{|l|}{ Vaginal carcinoma } \\
\hline Squamous cell carcinoma & 5 & $71.42 \%$ \\
\hline Malignant melanoma & 1 & $14.29 \%$ \\
\hline Lympho-epithelioma like carcinoma & 1 & $14.29 \%$ \\
\hline Total & 7 & $100 \%$ \\
\hline \multicolumn{3}{|l|}{ Ovarian } \\
\hline Epithelial tumour & & $78.85 \%$ \\
\hline Serous cystadenocarcinoma & 31 & \\
\hline Mucinous cystadenocarcinoma & 5 & \\
\hline Clear cell carcinoma & 5 & \\
\hline Germ cell tumour & & $11.54 \%$ \\
\hline Dysgerminoma & 5 & \\
\hline Struma ovarii & 1 & \\
\hline Sex cord stromal tumour & & $9.61 \%$ \\
\hline Granulosa cell tumour & 5 & \\
\hline Total & 52 & $100 \%$ \\
\hline
\end{tabular}

\section{TABLE 3: Site and histological pattern of gynaecological malignancies}

Serous adenocarcinoma was the most common histological type of epithelial ovarian cancer with 31 patients, and struma ovarii was the least, occurring only in one patient. All other tumours such as mucinous cystadenocarcinoma, clear cell carcinoma, dysgerminoma, and granulosa tumour were distributed equally.

\section{Discussion}

There were 18.1 million new cancer cases and 9.6 million cancer deaths worldwide in 2018, and nearly half of them were in Asia, as this region has nearly $60 \%$ of the global population [7].

The study showed cervical malignancies contributed 36\% of the genital tract malignancies. It was lower than the outcome of the study by Jamal et al. in Pakistan, where cervical malignancies accounting for $47 \%$ of all gynaecological cancers [8]; 61.5\% from Sokoto and 63.1\% from Port-Harcourt [9,10]; and studies in Enugu and Maiduguri, where $78 \%$ and $70.5 \%$ were documented, respectively $[11,1]$.

In the present study, cervical and ovarian malignancies were the commonest gynaecological malignancies accounting 36.36\% in each, followed by uterine (20.28\%), vaginal (4.9\%), and vulval (2.1\%).

The incidence of cervical and ovarian malignancies were $61.9 \%$ and $23.9 \%$, respectively, in a study by 
Madhutandra et al. [12]. The incidence of these tumours was $65.26 \%$ and $22.11 \%$ in a study by Chaudhary et al. [13]. While the incidence of cervical carcinoma and ovarian carcinomas were $86.1 \%$ and $4.68 \%$, respectively, in a study by Jhansivani et al. [14]. The study of Nasreen [15] reported ovarian cancer more than cervical cancer ( $48 \%, 24 \%$ respectively). Similarly, ovarian cancer was higher than cervical cancer in a study conducted in Tehran: $55.5 \%$ of former and $19.6 \%$ of the latter [16].

In Sri Lanka, cervical cancer was the third most common female cancer in 2014 and contributed 8.2\% of all female cancers. Ovarian cancer, the fourth most common female cancer, was $7.2 \%$ of all female cancers [6]. There was no well-established population-based cancer registry in Sri Lanka. Most of the data are from hospital- and laboratory-based active collection. Therefore, countrywide true data was not available for comparison. In addition, delayed health-seeking behaviour of the population was also common in developing countries, including Sri Lanka. These factors could be the reasons for the underestimation of the true incidence of the cancers.

Further, lesser incidence of teenage sexual activities in the studied region and improved coverage of Pap smear programme for early detection of premalignant dysplasia might have contributed in a less proportion of cervical malignancies in Batticaloa when compared with other developing countries.

The age range of the study population ranged from 19 to 79 years, and the peak incidence of cancer (55.2\%) was in the 40-59 years age range. The peak age range of incidence of cervical malignancies in this study was 40-59 years. This was consistent with the results of Yakasai et al., Briggs et al., and Jamal et al., who reported $46.25 \pm 4.99$ years, 42 years, and 47 years, respectively. The lower incidence of teenage sexual activities in the studied region and improved coverage of the Pap smear programme for early detection of premalignant dysplasia might have contributed to a lower proportion of cervical malignancies in Batticaloa when compared with other developing countries $[17,18,8]$.

This study was similar to studies done in the North-Eastern part of India, where the most common age group for carcinoma of the cervix was 51-60 years [19]. Another study in India also found that the most common age group for cancer cervix was 41.50 years (mean age $=49.53$ years) [20]. Ovarian cancer was contributing to $36.6 \%$ of all gynaecological cancers in this study. It was higher than what was reported in Kano by Yakasai et al. (17), in Maiduguri by Kyari et al. [1], in Enugu by Ugwu et al. [11], and in Enugu by Okeke et al. [21]. The incidence of ovarian cancer in this study was at a peak in the age of 40-59 years. This is similar to what is found in the literature [22], where it has been documented that worldwide, the highest incidence was in the 40-49 years age group.

The incidence of gynaecological malignancies was least in the young and old populations. The natural history of cervical cancer takes over 10 years to transform into the asymptomatic stage when the patient presents to the hospital. It is, therefore, unlikely to present earlier than 20 years of age. Further, most of the elderly population that develops the disease, because of the late presentation, might have died before the age of 70 years.

Overall, cervical and ovarian cancers accounted for almost $72.73 \%$ of the entire gynaecological malignancies in this study, and both of them had the same peak incidence in the 40-59 age group. The rest of the gynaecological cancers, including corpus uteri, vulva, and vaginal cancers accounted for the remaining $17.27 \%$. Thus, cancer continues to claim the lives of women in developing countries when they are critical to social and economic stability.

This study showed that $43.36 \%$ of total female genital tract tumours, such as cancer of cervix, vulva, and vagina, are Human Papilloma Virus (HPV)-associated cancers. They are not only preventable by certain strategies but also identifiable and manageable at the premalignant stage. This can be achieved through strengthening the primary and secondary preventive strategies in developing countries such as Sri Lanka.

the incidence and age-standardized rates of endometrium cancer for the world were $4.8 \%$ and $8.3 \%$, respectively; for India, they are $2.3 \%$ and $2.3 \%$, respectively [23]. In the US, 1 in 40 women develops endometrial cancer in her lifetime [24]. The incidence was higher in the white population of the US and lowest in India and Japan [24, 25]. In India, endometrial cancer ranks third among genital malignancies, after cancers of cervix and ovary [24]. In our study also, we have found similar results. In a study in India, the most common age group for carcinoma of endometrium was 51-60 years, with a mean age of 53.76 years; though the same had been reported as 55-64 years, with a mean age of 61.0 years [25]. In this study also, we found that the peak incidence of endometrial cancer was in the $40-59$ years age range.

\section{Limitations of the study}

This study shares the limitations expected in hospital-based secondary data research. Although this hospital is a Tertiary Care Teaching hospital, there may be patients who did not seek care from this hospital, such as those who trust private-sector Western health care or alternative medicine. Data collection was not from a tool primarily designed for this study and many variables may not be partly or fully covered. Since a paperbased health information system is used in this hospital, it is likely some patients may have been missed. There may a bias due to selective health-seeking by the high-risk population. 


\section{Conclusions}

Primary prevention is better and less expensive than tertiary prevention. The HPV-inflicted malignancies, such as cervical, vulval, and vaginal carcinomas, are preventable by certain strategies and identifiable at their pre-malignant stages by participating in a cancer-screening programme. Public health education aimed to establish personal abstinence from sex, avoiding sexual promiscuous behaviours, and using condoms in a high-risk sexual relationship could be commenced during teenage. In addition, the public could be encouraged for HPV vaccination for their school-going children. Policymakers should be mindful in improving the socio-economic status of the people for better living conditions, which can also decrease cancer incidence.

There are no recommended screening tests for ovarian cancer for women who do not have symptoms and are not at high risk of developing ovarian cancer. However, transvaginal ultrasound and CA-125 may be useful to screen women who have a high risk of ovarian cancer. Regarding ovarian cancer, improvement in awareness of the symptoms of ovarian cancer is helpful in diagnosing the condition at an early stage. General practitioners and women need to know that women with ovarian cancer do experience symptoms, even though they are non-specific, more frequently, severely, and persistently than those without the disease. Seeking medical advice early without delay when these symptoms develop is vital for a better prognosis.

\section{Additional Information \\ Disclosures}

Human subjects: Consent was obtained or waived by all participants in this study. Animal subjects: All authors have confirmed that this study did not involve animal subjects or tissue. Conflicts of interest: In compliance with the ICMJE uniform disclosure form, all authors declare the following: Payment/services info: All authors have declared that no financial support was received from any organization for the submitted work. Financial relationships: All authors have declared that they have no financial relationships at present or within the previous three years with any organizations that might have an interest in the submitted work. Other relationships: All authors have declared that there are no other relationships or activities that could appear to have influenced the submitted work.

\section{References}

1. Kyari O, Nggada H, Mairiga A: Malignant tumours of female genital tract in North Eastern Nigeria . East Afr Med J. 2004, 81:142-145. 10.4314/eamj.v81i3.9144

2. Nkyekyer K: Pattern of gynaecological cancers in Ghana . East Afr Med J. 2000, 77:534-538. 10.4314/eamj.v77i10.46708

3. Stewart BW, Kleihues P: Cancers of female reproductive tract. World Cancer Report 2003. Stewart BW, Kleihues P (ed): IARC Press, Lyon; 2003.

4. Franco EL, Franco ED, Ferenczy A: Cervical cancer: epidemiology, prevention and the role of human papilloma virus infection. Canadian Med Assoc J. 2001, 164:1017-1025.

5. Parkin DM, Muir CS: Cancer incidence in five continents: comparability and quality of data . IARC Scientific Publications. 1992, 120:45-173.

6. National Cancer Control Programme: Cancer Incidence Data Sri Lanka 2014. National Cancer Control Programme, Colombo; 2014.

https://www.health.gov.lk/moh_final/english/public/elfinder/files/publications/2018/Cancer\%20Incidence\%20in\%20Sri\%20I

7. Bray F, Ferlay J, Soerjomataram I, Siegel RL, Torre LA, Jemal A: Global cancer statistics 2018: GLOBOCAN estimates of incidence and mortality worldwide for 36 cancers in 185 countries. Cancer J Clin. 2018, 68:394424. 10.3322/caac. 21492

8. Jamal S, Mamoon N, Mushtaq S, Luqman M, Moghal S: The pattern of gynecological malignancies in 968 cases from Pakistan. Ann Saudi Med. 2006, 26:382-384. 10.5144/0256-4947.2006.382

9. Airede LR, Malami SA: A five-year review of female genital tract malignancies in Sokoto North-Western Nigeria. Mary Slessor J Med. 2005, 5:51-56. 10.4314/msjm.v5i1.11044

10. Nwosu SO, Anya SE: Malignancies of the female genital tract at the University of Port-Harcourt Teaching Hospital. Niger Postgrad Med J. 2004, 11:107-109.

11. Ugwu EO, Iferikigwe ES, Okeke TC, Ugwu AO, Okezie OA, Agu PU: Pattern of gynaecological cancers in University of Nigeria Teaching Hospital, Enugu, south-eastern Nigeria. Niger J Med. 2011, 20:266-269.

12. Madhutandra S, Konar H, Raut D: Clinico-pathological features of gynecological malignancies in a tertiary care hospital in eastern india: importance of strengthening primary health care in prevention and early detection. Asian Pac J Cancer Prev. 2013, 14:3541-3545. 10.7314/APJCP.2013.14.6.3541

13. Chaudhary S, Singhal SR, Latika, Gupta A: Study of sociodemographic profile and pattern of gynaecological malignancies in a tertiary care center. Int J Reprod Contracept Obstet Gynecol. 2016, 5:2640-2643. 10.18203/2320-1770.ijrcog20162636

14. Jhansivani Y, Rani S: Epidemiology of gynaelogical cancers in a tertiary care center (Government General Hospital, Gutur). IOSR J Dent Med Sci. 2015, 14:41-45.

15. Nasreen F: Pattern of gynaecological malignancies in tertiary hospital . J Postgrad Med Inst (PeshawarPakistan). 2002, 16:215-220.

16. Torpy JM, Burke AE, Golub RM: Ovarian cancer. JAMA. 2011, 305:2484-2484. 10.1001/jama.305.23.2484

17. Yakasai IA, Ugwu EA, Otubu J: Gynaecological malignancies in Aminu Kano Teaching Hospital, Kano: A 3 year review. Niger J. Clin Pract. 2013, 16:63-66. 10.4103/1119-3077.106768

18. Briggs ND, Katchy KC: Pattern of primary gynaecological malignancies as seen in a tertiary hospital situated in the Rivers state of Nigeria. Int J Gynecol Obstet. 1990, 31:157-161. 10.1016/0020-7292(90)90714-V

19. Sreedevi A, Javed R, Dinesh A: Epidemiology of cervical cancer with special focus on India . Int J Womens 


\section{Cureus}

Health. 2015, 7:405-414. 10.2147/IJWH.S50001

20. Kulshreshtha AR, Kulshreshtha R, Kulshreshtha MR: The pattern of occurrence of female genital tract malignancies at a tertiary care centre in Northern India in last ten years. Indian J Obstet Gynecol Res. 2017, 4:440-445.

21. Okeke TC, Onah N, Ikeako LC, Ezenyeaku CCT: The frequency and pattern of female genital tract malignancies at the University of Nigeria Teaching Hospital, Enugu, Nigeria. Ann Med Health Sci Res. 2013, 3:345-348.

22. Klufio CA: Epithelial ovarian carcinoma. Comprehensive Gynaecology in the Tropics. Kwuwukume EY, Emuveyan EE (ed): Graphic Packaging Ltd, Accra; 2005. 449-471.

23. Park K: Epidemiology of chronic and non-communicable diseases. Park's Textbook of Preventive and Social Medicine. Park K (ed): Banarasidas Bhanot, Jabalpur; 2015. 381-382.

24. Konar H: Genital malignancy. DC Dutta’s Textbook of Gynaecology. Dutta DC (ed): Kolkata; 2016. 292.

25. Howlader N, Noone AM, Krapcho M, et al.: SEER Cancer Statistics Review, 1975-2008. National Cancer Institute, Bethesda; 2011. 